\title{
Evaluation of Serum Glucagon-Like Peptide 1 and Vitamin D Levels in Elderly Patients with Bone Fractures
}

\author{
Özhan Pazarci ${ }^{a}$ Halef Okan Dogan ${ }^{b}$ Seyran Kilinc ${ }^{a}$ Yalkin Çamurcu ${ }^{c}$ \\ a Department of Orthopedics and Traumatology, Cumhuriyet University School of Medicine, Sivas, Turkey; \\ ${ }^{\mathrm{b}}$ Department of Biochemistry, Cumhuriyet University School of Medicine, Sivas, Turkey; ${ }^{\mathrm{C} D e p a r t m e n t}$ of \\ Orthopedics and Traumatology, Erzincan University School of Medicine, Erzincan, Turkey
}

\section{Highlights of the Study}

- Serum vitamin D and glucagon-like peptide-1 (GLP-1) levels were assessed in elderly patients with bone fractures.

- Serum GLP-1 levels were significantly lower in elderly patients with bone fractures than in healthy elderly adults.

- A significant correlation was found between decreased vitamin D and GLP-1 levels.

\section{Keywords}

Bone · Fracture · Elderly patients · Glucagon-like peptide-1 . Vitamin D

\section{Abstract \\ Objectives: To evaluate the correlation between levels of se- rum vitamin D and glucagon-like peptide-1 (GLP-1) in elder- ly patients with bone fractures. Materials and Methods: This study included 56 patients and 31 control subjects. The pa- tients included were those aged $\geq 65$ years who were admit- ted to our hospital with a diagnosis of bone fracture. The control group comprised age-matched, healthy individuals. Levels of serum vitamin D and GLP-1 were measured and compared between the 2 groups. Results: Significant differ- ences were noted between the groups in terms of serum lev- els of vitamin $\mathrm{D}(p<0.001)$ and serum levels of GLP-1 ( $p<$ 0.001 ). A positive correlation was observed between serum}

levels of vitamin D and GLP-1. Conclusion: Serum levels of GLP-1 were found to be significantly lower in elderly patients with bone fracture compared to healthy adults. In addition, a significant correlation was found between decreased vitamin D and GLP-1 levels. These results may therefore demonstrate the protective effects of GLP-1 on bone structure and metabolism, similar to those of vitamin D.

(c) 2019 The Author(s)
Published by S. Karger AG, Basel

\section{Introduction}

Aging is defined as time-dependent changes in an organism leading to a functional decline and an increased risk of disease [1]. It is estimated that the elderly population will grow dramatically in the next 20 years in most Western countries [2]. With an increased life expectancy,

\begin{tabular}{|c|c|c|}
\hline KARGER & $\begin{array}{l}\text { () } 2019 \text { The Author(s) } \\
\text { Published by S. Karger AG, Basel }\end{array}$ & $\begin{array}{l}\text { Karger } \\
\text { Open access }\end{array}$ \\
\hline $\begin{array}{l}\text { karger@karger.com } \\
\text { www.karger.com/mpp }\end{array}$ & $\begin{array}{l}\text { This is an Open Access article licensed u } \\
\text { Attribution-NonCommercial- } 4.0 \text { Intern } \\
\text { (http://www.karger.com/Services/Open } \\
\text { the online version of the article only. Usa } \\
\text { mercial purposes requires written perm }\end{array}$ & $\begin{array}{l}\text { rt the Creative Commons } \\
\text { nal License (CC BY-NC) } \\
\text { essLicense), applicable to } \\
\text { and distribution for com- } \\
\text { on. }\end{array}$ \\
\hline
\end{tabular}

Özhan Pazarc1

Department of Orthopedics and Traumatology

Cumhuriyet University School of Medicine, Central campus

TR-58000 Sivas (Turkey)

E-Mail dr.pazarci@gmail.com 
there is a parallel increased risk of developing debilitating diseases [3]. Aging causes adverse medical outcomes in bone metabolism, including decreased skeletal fragility and bone turnover. Therefore, the elderly are at a high risk of bone fractures [4].

There is increased interest in the effects of gut hormones on metabolism, and this relationship has been defined as the "gut-bone axis" [5]. The gut peptides secreted when food is ingested are defined as incretins. Glucose-dependent insulinotropic polypeptide (GIP; gastric inhibitory polypeptide) is a well-known incretin [6]. Overall, studies in both humans and rodents have indicated that GIP is a pivotal and direct regulator of bone metabolism, with direct anabolic effects on osteoblasts and an antiresorptive effect on osteoclasts [7]. Glucagon-like peptide-1 (GLP-1) is also a member of the incretin hormone family, which plays an important role in regulating energy metabolism by stimulating insulin secretion [8], and GLP-1 receptor agonists are used in the management of type 2 diabetes mellitus. GLP-1 is also a potent modulator in the regulation of bone mass, quality, and strength [9]. In experimental animal models, it has been shown that inhibition of GLP-1 decreases bone resorption [10]. However, little is known about the relationship between serum levels of GLP-1 and bone fractures in elderly patients. Vitamin $\mathrm{D}$ is important for bone health and calcium hemostasis [11]. Low levels of 25-hydroxyvitamin D are associated with a loss of muscle strength, a low or decreased physical performance, functional limitations and decline, falls, and fractures [12]. Previous studies have revealed a strong correlation between GLP-1 and vitamin $\mathrm{D}$; however, the relationship between serum levels of GLP-1 and vitamin D in bone fractures has not been fully elucidated.

In this study, serum vitamin D and GLP-1 levels were assessed in elderly patients with bone fractures. The correlation between serum vitamin D and GLP-1 levels in these patients was also evaluated. This study was aimed at contributing to the knowledge regarding GLP-1 and vitamin D levels in elderly patients with bone fractures.

\section{Materials and Methods}

\section{Study Population}

This study included patients who were admitted to our university hospital and diagnosed with a bone fracture between May and October 2017. The exclusion criteria for the control group included: clinical suspicion of infections, the presence of liver disease, kidney disease, diabetes mellitus, alcohol consumption, rheumatic
Table 1. Bone fracture locations

\begin{tabular}{lrr}
\hline Bone & $n$ & $\%$ \\
\hline Femur proximal & 35 & 40.2 \\
Femur diaphysis & 6 & 6.9 \\
Forearm and hand & 4 & 4.6 \\
Humerus proximal & 3 & 3.4 \\
Foot and ankle & 3 & 3.4 \\
Tibia diaphysis & 3 & 3.4 \\
Pelvis & 2 & 2.3 \\
\hline Total & 56 & 100 \\
\hline
\end{tabular}

Table 2. Comparison of GLP-1 and vitamin D levels between female and male fracture patients

\begin{tabular}{lccl}
\hline Parameter & Females $(n=29)$ & Males $(n=27)$ & $p$ values \\
\hline Age, years & $77.79 \pm 8.29$ & $76.85 \pm 7.67$ & 0.662 \\
BMI & $26.56 \pm 3.82$ & $25.75 \pm 3.51$ & 0.292 \\
GLP-1, ng/mL & $125.86 \pm 67.64$ & $121.94 \pm 57.95$ & 0.817 \\
Vitamin D, ng/mL & $10.25 \pm 8.98$ & $10.25 \pm 8.98$ & 0.903 \\
\hline
\end{tabular}

Values are presented as means $\pm \mathrm{SD}$.

disease, malignancy, and smoking. Patients with a history of diabetes mellitus, thyroid or parathyroid disorders, or impaired renal or kidney function were excluded from this study.

\section{Collection and Analysis of Blood}

Overnight fasting blood samples were collected from all of the participants into serum tubes (Becton Dickinson, UK). The blood was allowed to clot and then centrifuged at $4^{\circ} \mathrm{C}$ for $15 \mathrm{~min}$ at 3,500 $\mathrm{rpm}$; the serum was aliquoted and immediately frozen at $-80^{\circ} \mathrm{C}$ (WiseCryo, South Korea). The quantitative sandwich enzymelinked immunosorbent assay technique (YHBioscience, Shanghai, China) was used to determine serum levels of GLP-1. Tests were performed according to the manufacturer's instructions. Serum 25-hydroxyvitamin D levels were measured using the electrochemiluminescence immunoassay method (Cobas e601, Roche, Germany).

\section{Statistical Analysis}

Statistical analyses were performed using SPSS 22.0 software (SPSS Inc., IBM, USA). Numerical continuous variables were stated as means \pm SD and categorical variables as numbers (\%). Comparison of variables was performed using Student's $t$ test or the Mann-Whitney U test according to the results of the Shapiro-Wilk normality test. Comparisons of frequencies were made with Pearson's $\chi^{2}$ test. The correlation between serum vitamin $\mathrm{D}$ levels and GLP-1 levels was examined using Spearman's correlation test. $p<$ 0.05 was considered statistically significant. The figures were obtained using R software (version R-3.5.2 for Windows). 
Fig. 1. Comparison of GLP-1 concentrations between the patient and control groups. Central lines show median values; box limits indicate the 25th and 75th percentiles as determined by R software; whiskers extend 1.5 times the IQR from the 25 th and 75th percentiles, and outliers are represented by dots; data points are plotted as circles.

Fig. 2. Comparisons of vitamin D concentrations between the patient and control groups. Central lines show median values; box limits indicate the 25th and 75th percentiles as determined by R software; whiskers extend 1.5 times the IQR from the 25 th and 75th percentiles, and outliers are represented by dots; data points are plotted as circles. $n=53 ; 45$ sample points.
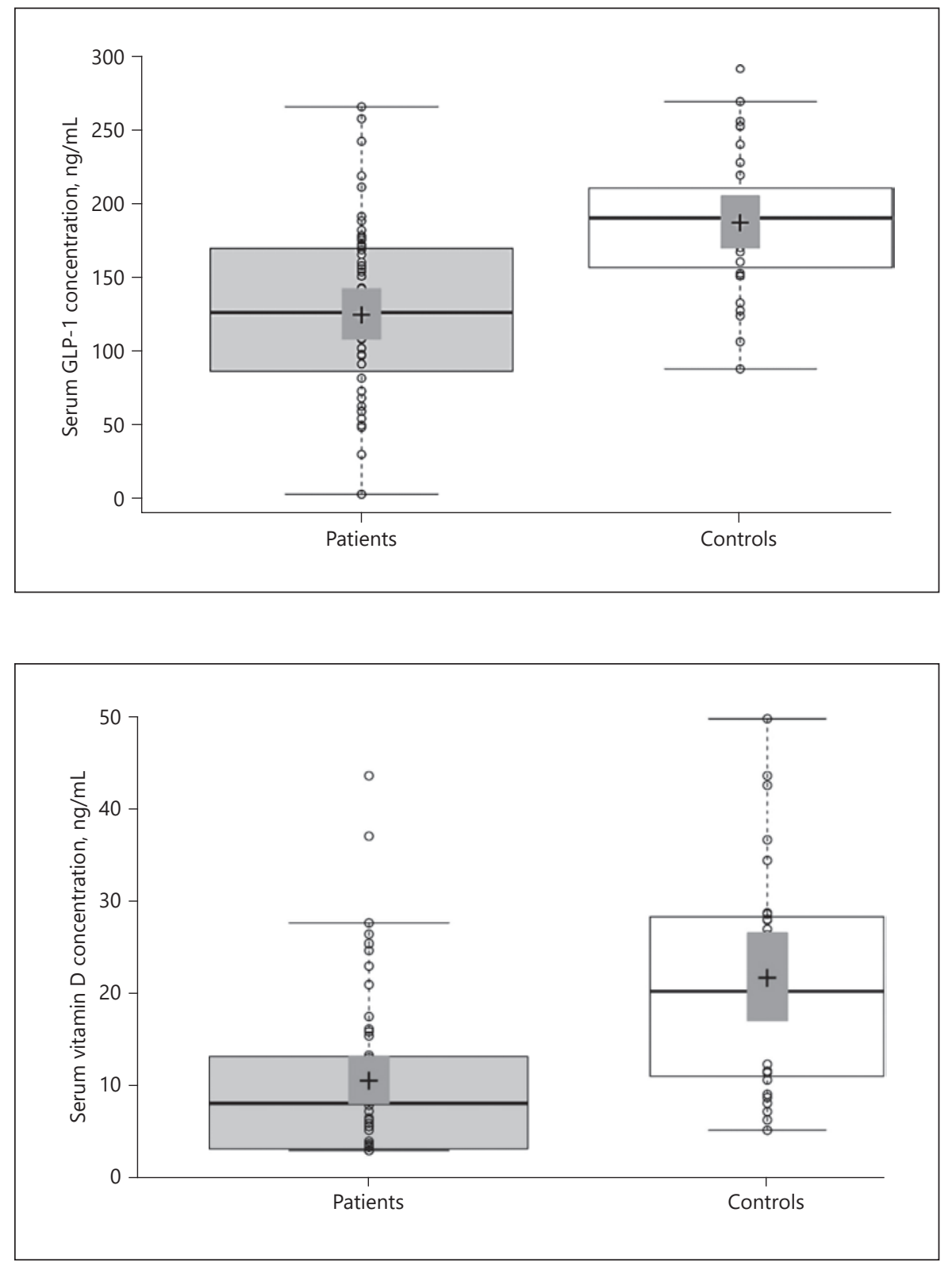

\section{Results}

A total of 56 patients ( 29 females and 27 males; mean age: $77.25 \pm 7.7)$ were studied. The control group of 31 subjects comprised 14 females and 17 males (mean age: $71.58 \pm 4.8)$. No statistically significant differences were found between the groups in terms of age $(p>0.05)$ or gender $(p>0.05)$. Thirty-five patients had a proximal femur fracture and 6 patients had a femur diaphysis fracture. The distribution of fracture locations is shown in Table 1. Mean GLP-1 concentrations were measured as
$123.9 \pm 62.6 \mathrm{ng} / \mathrm{mL}$ in the patient group and $186.4 \pm 48.0$ $\mathrm{ng} / \mathrm{mL}$ in the control group $(p<0.001)$ (Fig. 1). The mean serum concentration of vitamin $\mathrm{D}$ was $10.3 \pm 8.8 \mathrm{ng} / \mathrm{mL}$ in the patient group and $21.0 \pm 12.1 \mathrm{ng} / \mathrm{mL}$ in the control group $(p<0.001)$ (Fig. 2). No statistically significant differences were observed between female and male patients in terms of GLP-1 and vitamin D concentrations or the mean BMI (Table 2). A positive correlation was determined between serum vitamin D and GLP-1 concentrations. $(p=0.024, r=0.241)$ (Fig. 3). 


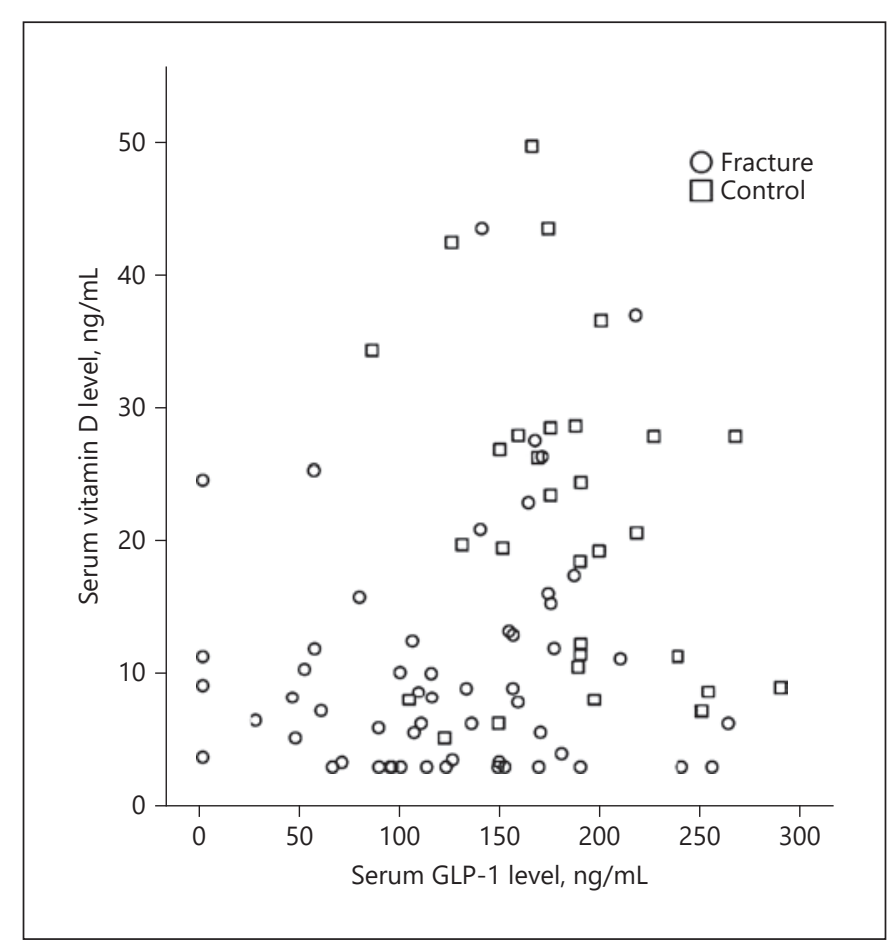

Fig. 3. Scatterplot matrix between serum vitamin D and GLP-1 levels.

\section{Discussion}

The most important findings of this study were the decreased serum levels of GLP-1 and vitamin D in elderly patients with bone fracture. These results suggest the importance of GLP-1 levels in bone metabolism. Bone fractures require expensive and difficult treatments, entailing high costs of treatment and rehabilitation, a loss of workforce, and potential complications [13]. Understanding fracture metabolism is an important prerequisite for the development of potential therapeutic targets and the prevention of some fracture types such as osteoporotic hip fracture [14].

To the best of our knowledge, no study to date has investigated serum GLP-1 in patients with and without bone fracture. The results of this study are of value as they indicate that the serum levels of GLP-1 were significantly decreased in the bone fracture group. GLP-1 is secreted by intestinal $L$ cells [15], regulated by intraluminal contents, neural stimuli, and hormones. GLP-1 receptors are found in the pancreas, the gastrointestinal tract, thelungs, the heart, the kidneys and several regions of the brain, the liver, and skeletal muscles [16]. The presence of these receptors in bone was controversial until it was demonstrat- ed in the study by Pereira et al. [17]. Animal studies have shown that GLP-1 activity is necessary for musculoskeletal system physiology. It has been shown that GLP-1 receptor knockout mice have reduced trabecular bone volume, bone strength, and cortical bone thickness $[6,18]$. These data suggest that a functional level of GLP-1 is required not only for the control of bone resorption but also for the preservation of optimal bone matrix quality [19].

The correlation between fractures and GLP-1 is controversial. In studies on patients using GLP-1 agonists, the fracture risk was observed to neither increase nor decrease $[10,20]$. Previous studies have also emphasized that the fracture risk varies according to the type of GLP1 agonist used. For example, diabetic patients using liraglutide have been observed to have a reduced fracture risk compared to those using other antidiabetics or placebo [10]. This variability of the effects of types of GLP-1 agonists may be attributed to the fact that liraglutide is most similar to endogenous GLP-1 [10]. The current literature is insufficient to explain the effect of GLP-1 and the associated medications on bone fracture risk. The results of the current study showing lower serum levels of GLP-1 in the bone fracture group contributes new information to the literature.

On the other hand, the insulotropic and bone resorption protective effects of GIP, which is a member of the incretin hormone family, have been shown in previous studies [5]. The effect of GLP-1 on bone metabolism is less clear according to the available data in the literature, although Bergmann et al. [7] showed that GIP and GLP-1 together have partially additive bone resorption inhibitory effects. Furthermore, the demonstration of a relationship between insulin, GLP-1, and osteocalcin revealed the function of bone as an endocrine organ [21, 22]. A better understanding of the effects of GIP and GLP-1 on bone metabolism could revolutionize future treatment of osteoporosis [23].

Lower median levels of vitamin D were observed in the bone fracture group in this study. This finding is in accordance with the study by Thompson et al. [24]. A metaanalysis by Sprague et al. [25] revealed that vitamin D deficiency is widespread among patients with fractures. The relationship between vitamin $\mathrm{D}$ and bone is complex. Maintaining optimal vitamin D levels is important for bone health [11], and a reduced vitamin D level is known to increase the risk of fractures [24]. In addition, a metaanalysis of double-blinded randomized controlled trials showed that oral vitamin $\mathrm{D}$ supplementation reduced the risk of fractures [26]. 
In the current study, a correlation was noted between serum vitamin D and GLP-1 levels in fracture patients. Enciso et al. [27] reported that vitamin D increased GLP1 secretion in both in vivo and in vitro environments with an insulinotropic effect. Similarly, a correlation between serum vitamin D and GLP-1 levels was noted in the current study. It can be seen that there could be beneficial effects for fracture patients in the correlation between vitamin D and GLP-1 with respect to new therapeutic approaches.

There are some limitations to this study. First, there was no evaluation of bone mineral density or the dietary conditions of the patients to determine the cause of low vitamin D levels. However, patients with endocrine disorders were excluded in order to identify those with impaired metabolic vitamin D and GLP-1. The strength of this study is that it is the first prospective case-control study in the literature to evaluate serum vitamin $\mathrm{D}$ and GLP-1 levels in elderly patients with bone fractures in comparison to healthy individuals. It is also the first study in the literature to show a correlation between serum vitamin D and GLP-1 levels. Further well-designed randomized studies in large populations are required to reach a higher level of evidence to prove the relationship between vitamin D and GLP-1 metabolisms and their impact on bone metabolism.

\section{Conclusion}

Our results demonstrated that serum GLP-1 levels were significantly lower in elderly patients with bone fractures than in healthy elderly adults. In addition, a significant correlation was found between decreased vitamin D and GLP-1 levels. We infer that the protective effects of GLP-1 on bone structure and metabolism are similar to the effects of vitamin D. This study can also be taken as a guide for future studies investigating the effect of GLP-1 metabolism and GLP-1 agonists with vitamin D and bone metabolism in the prevention of fractures in elderly patients due to impaired bone quality.

\section{Acknowledgement}

This work was supported by the Scientific Research Project Fund of Cumhuriyet University (project No. T724).

\section{Statement of Ethics}

This prospective case-control study was done after approval from the ethics committee of the institutional review board and it was conducted in accordance with the Declaration of Helsinki. Informed consent was obtained from each participant.

\section{References}

1 López-Otín C, Blasco MA, Partridge L, Serrano M, Kroemer G. The hallmarks of aging. Cell. 2013 Jun;153(6):1194-217.

2 Divo MJ, Martinez CH, Mannino DM. Ageing and the epidemiology of multimorbidity. Eur Respir J. 2014 Oct;44(4):1055-68.

3 Niccoli T, Partridge L. Ageing as a risk factor for disease. Curr Biol. 2012 Sep;22(17):R74152.

4 Demontiero O, Vidal C, Duque G. Aging and bone loss: new insights for the clinician. Ther Adv Musculoskelet Dis. 2012 Apr;4(2):61-76.

5 Schiellerup SP, Skov-Jeppesen K, Windeløv JA, Svane MS, Holst JJ, Hartmann B, et al. Gut hormones and their effect on bone metabolism: potential drug therapies in future osteoporosis treatment. Front Endocrinol (Lausanne). 2019 Feb;10:75

6 Yamada C, Yamada Y, Tsukiyama K, Yamada K, Udagawa N, Takahashi N, et al. The murine glucagon-like peptide-1 receptor is essential for control of bone resorption. Endocrinology. 2008 Feb;149(2):574-9.

7 Bergmann NC, Lund A, Gasbjerg LS, Jørgensen NR, Jessen L, Hartmann B, et al. Separate and Combined Effects of GIP and GLP-1
Infusions on Bone Metabolism in Overweight Men Without Diabetes. J Clin Endocrinol Metab. 2019 Jul;104(7):2953-60.

8 Seino Y, Fukushima M, Yabe D. GIP and GLP-1, the two incretin hormones: similarities and differences. J Diabetes Investig. 2010 Apr;1(1-2):8-23.

9 Weisnagel SJ. The role of glucagon-like peptide-1 receptor agonists in cardiovascular disease prevention in type 2 diabetes mellitus: evidence from the most recent clinical trials. Ann Transl Med. 2018 May;6(10): 194-194.

10 Zhao C, Liang J, Yang Y, Yu M, Qu X. The impact of glucagon-like peptide-1 on bone metabolism and its possible mechanisms. Front Endocrinol (Lausanne). 2017 May;8:98.

11 Bikle DD. Vitamin D and bone. Curr Osteoporos Rep. 2013;10:151-9.

12 Van Schoor NM, Heymans MW, Lips P. Vitamin D status in relation to physical performance, falls and fractures in the Longitudinal Aging Study Amsterdam: a reanalysis of previous findings using standardized serum 25 -hydroxyvitamin D values. J Steroid Biochem Mol Biol. 2018 Mar;177:255-60.
13 Giannoudis PV, Einhorn TA, Marsh D. Fracture healing: the diamond concept. Injury. 2007;38:3-6.

14 Dimitriou R, Tsiridis E, Giannoudis PV. Current concepts of molecular aspects of bone healing. Injury. 2005 Dec;36(12):1392-404.

15 Orskov C, Rabenhøj L, Wettergren A, Kofod $\mathrm{H}, \mathrm{Holst} J \mathrm{~J}$. Tissue and plasma concentrations of amidated and glycine-extended glucagonlike peptide I in humans. Diabetes. 1994 Apr; 43(4):535-9.

16 Baggio LL, Drucker DJ. Biology of incretins: GLP-1 and GIP. Gastroenterology. 2007 May; 132(6):2131-57.

17 Pereira M, Jeyabalan J, Jørgensen CS, Hopkinson M, Al-Jazzar A, Roux JP, et al. Chronic administration of glucagon-like peptide-1 receptor agonists improves trabecular bone mass and architecture in ovariectomised mice. Bone. 2015 Dec;81:459-67.

18 Gaudin-Audrain C, Irwin N, Mansur S, Flatt PR, Thorens B, Baslé M, et al. Glucose-dependent insulinotropic polypeptide receptor deficiency leads to modifications of trabecular bone volume and quality in mice. Bone. 2013 Mar;53(1):221-30.
Serum Glucagon-Like Peptide 1 and Vitamin D Levels in Bone Fractures
Med Princ Pract 2020;29:219-224

DOI: $10.1159 / 000502132$ 
19 Mabilleau G. Interaction entre l'os et les hormones incrétines: une revue. Morphologie. 2017;101:9-18.

20 Mansur SA, Mieczkowska A, Bouvard B, Flatt PR, Chappard D, Irwin N, et al. Stable Incretin Mimetics Counter Rapid Deterioration of Bone Quality in Type 1 Diabetes Mellitus. J Cell Physiol. 2015 Dec;230(12):3009-18.

21 Lee NK, Sowa H, Hinoi E, Ferron M, Ahn JD, Confavreux C, et al. Endocrine regulation of energy metabolism by the skeleton. Cell. 2007 Aug;130(3):456-69.

22 Mizokami A, Yasutake Y, Gao J, Matsuda M, Takahashi I, Takeuchi H, et al. Osteocalcin induces release of glucagon-like peptide- 1 and thereby stimulates insulin secretion in mice. PLoS One. 2013;8(2):e57375.
23 Ma X, Meng J, Jia M, Bi L, Zhou Y, Wang Y, et al. Exendin-4, a glucagon-like peptide-1 receptor agonist, prevents osteopenia by promoting bone formation and suppressing bone resorption in aged ovariectomized rats. J Bone Miner Res. 2013 Jul;28(7):1641-52.

24 Thompson RM, Dean DM, Goldberg S, Kwasny MJ, Langman CB, Janicki JA. Vitamin D Insufficiency and Fracture Risk in Urban Children. J Pediatr Orthop. 2017 Sep; 37(6):368-73.
25 Sprague S, Petrisor B, Scott T, Devji T, Phillips $\mathrm{M}$, Spurr $\mathrm{H}$, et al. What is the role of vitamin $\mathrm{D}$ supplementation in acute fracture patients? A systematic review and meta-analysis of the prevalence of hypovitaminosis D and supplementation efficacy. J Orthop Trauma. 2016 Feb;30(2):53-63.

26 Holick MF, Binkley NC, Bischoff-Ferrari HA, Gordon CM, Hanley DA, Heaney RP, et al.; Endocrine Society. Evaluation, treatment, and prevention of vitamin D deficiency: an Endocrine Society clinical practice guideline. J Clin Endocrinol Metab. 2011 Jul;96(7): 1911-30.

27 Enciso PL, Wang L, Kawahara Y, Sakamoto S, Shimada S, Takeichi Y, et al. Dietary vitamin D3 improves postprandial hyperglycemia in aged mice. Biochem Biophys Res Commun. 2015 May;461(1):165-71. 